\title{
Numerical Simulation of Residual Stresses in Thermal Barrier Coating Due to Thermal Mismatch
}

\author{
Bai Yumei \\ Shan Xi University, Taiyuan 030013, China \\ baiyumei@sxu.edu.cn
}

Keywords: residual stress; thermal barrier coating (TBC); maximal stress; interfacial stress Abstract: A plane strain geometrical model of thermal barrier coating (TBC) is established in order to investigate the distributed characters of maximal stresses in ceramic and interfacial ones. The effects of temperature and ceramic thickness on stresses are also studied. The results show that the stress in ceramic layer is mainly for lateral compressive one, and its maximal stress occurs in the place that is at the distance of 1/3 thickness from coating surface.; The interracial stresses are comparatively feeble, but concentrate at the free edge. And that the increase of temperature makes stresses to rise. Increase of coating's thickness changes the distribution of stresses in the direction of thickness and makes residual stresses and interfacial stresses reduction.

\section{Introduction}

Thermal barrier coating(TBC) has been widely used in various fields. It can provide effective insulation and antioxidant functions for components, and can improve the reliability of mechanical products and extend its service life. However, due to thermal expansion mismatch, thermal barrier coating is subject to residual stresses, which can cause delamination and failure between different layers[1]. And in the process of thermal cycling cooling, the residual stress in thermal barrier coating is the main reason for the failure. So it is very important to research the interface stress. Many scholars [2-4] has also done a lot of research in this area, but few people payed attention to the influence of temperature and coating thickness on the material internal stresses and the interface stresses. In this paper, a plane strain geometrical model with Tri-layer coating system: ceramic layer, hot oxidation layer, and bonding is advanced to research the influence of different thickness and different temperature variations between different layers on the residual stress.

\section{Analysis}

The cross-section of TBC is shown in Fig. 1, which including a $0.1 \mathrm{~mm} \mathrm{ZrO} 2 \sim 8 \% \mathrm{Y} 2 \mathrm{O} 3$ ceramic layer, a $0.01 \mathrm{~mm}^{\mathrm{Al}_{2} \mathrm{O}_{3}}$ thermally grown oxide (TGO) layer, a $0.05 \mathrm{~mm} \mathrm{NiCoCrAlY}$ bond coat layer and a $2 \mathrm{~mm}{ }^{1 \mathrm{Cr}_{18}} \mathrm{Ni}_{9} \mathrm{Ti}$ alloy substrate. Since the dimension perpendicular to the cross-sectional with respect to the other two directions is much greater, so it is a plane strain problem.

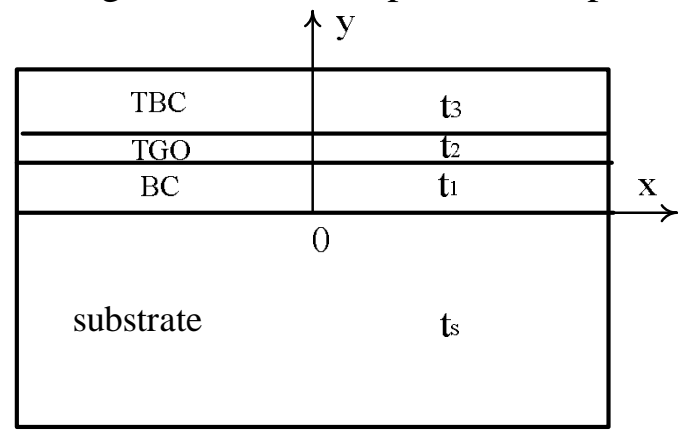

Fig. 1 The schematic of the model's cross-section

The properties required for the model are listed in Table 1[4,5] .Suppose the interfaces between different layers are assumed to be the ideal thermal contact, that is, continuous temperature and heat flow. Heat radiation and heat conduction on the system's edge are neglected. The ceramic layer surface 
is heated to $\mathrm{T}$ for 40 minutes, and then is cooled to room temperature $25{ }^{\circ} \mathrm{C}$. The residual stresses caused by preparation process can be neglected, due to the study has showed that thermal barrier coating preparation temperature has a little influence on residual stress in the system[6]. The heat transfer coefficient of $30 \mathrm{~W} /\left(\mathrm{m}^{2} \cdot{ }^{\circ} \mathrm{C}\right)$ is assumed in the substrate surface. In the paper, the effect of temperature and coating thickness on the thermal stress is discussed.

Table 1 Material parameters used in the models ${ }^{[4,5]}$

\begin{tabular}{ccccc}
\hline & $\begin{array}{c}\text { Young's modulus } \\
\mathrm{E}(\mathrm{GPa}))\end{array}$ & $\begin{array}{c}\text { Poisson's ratio } \\
\mu\end{array}$ & $\begin{array}{c}\text { coefficient of thermal expansions } \\
\alpha\left(10^{-6} /{ }^{\circ} \mathrm{C}\right)\end{array}$ & $\begin{array}{c}\text { conductivity } \\
k \text { W/ } /\left(\mathrm{m} \cdot{ }^{\circ} \mathrm{C}\right)\end{array}$ \\
\hline TBC & 50 & 0.1 & 13.9 & 1.8 \\
TGO & 360 & 0.27 & 8.0 & 30 \\
BC & 200 & 0.3 & 15.2 & 16.1 \\
substate & 184 & 0.24 & 16.6 & 16.3 \\
\hline
\end{tabular}

\section{Discussion}

Figure 2 shows variation of stress $\sigma \mathrm{xx}$ along the $\mathrm{y}$-axis for the different temperature: $\mathrm{T}=850^{\circ} \mathrm{C}, 1000^{\circ} \mathrm{C}, 1150^{\circ} \mathrm{C}$. The stresses rise with increasing temperature, and the higher the temperature, the greater the change in the stresses of each layer. The stress curve was " $\mathrm{V}$ " type in the ceramic layer, and its maximal compressive stress occurs in the place that is at the distance of $1 / 3$ thickness from coating surface. $\sigma y y$ and $\sigma x y$ along the thickness direction are small relatively.

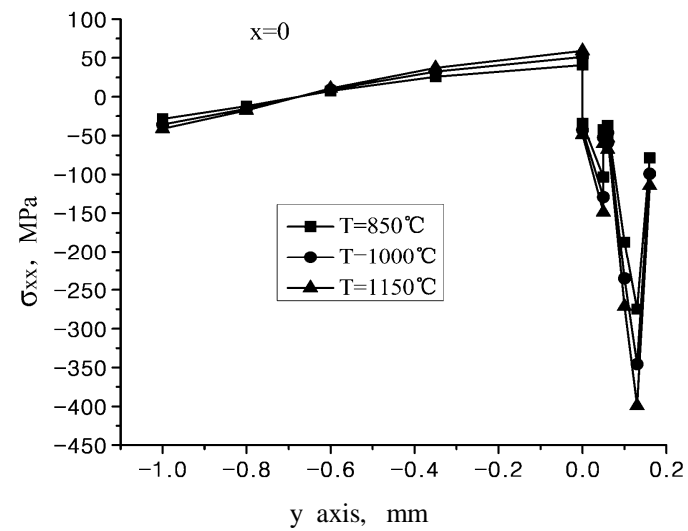

Fig.2 Variation of stress $\sigma_{\mathrm{xx}}$ along the $\mathrm{y}$-axis for different temperature

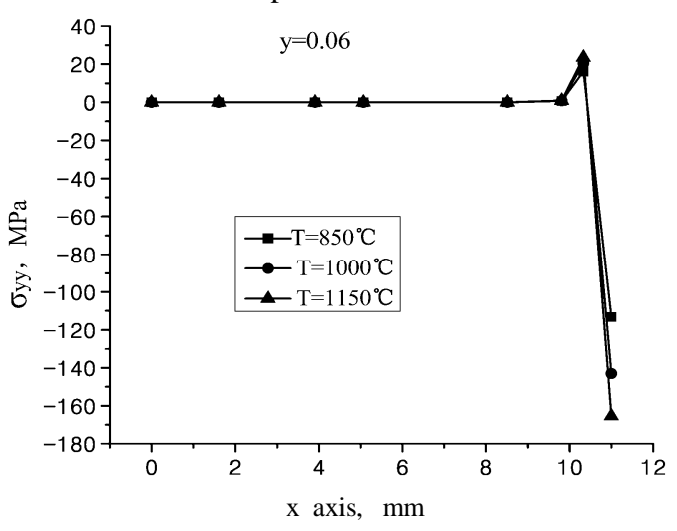

Fig.4 Variation of ceramic interfacial stress $\sigma_{\mathrm{yy}}$ along the $\mathrm{x}$-axis for different temp temperature

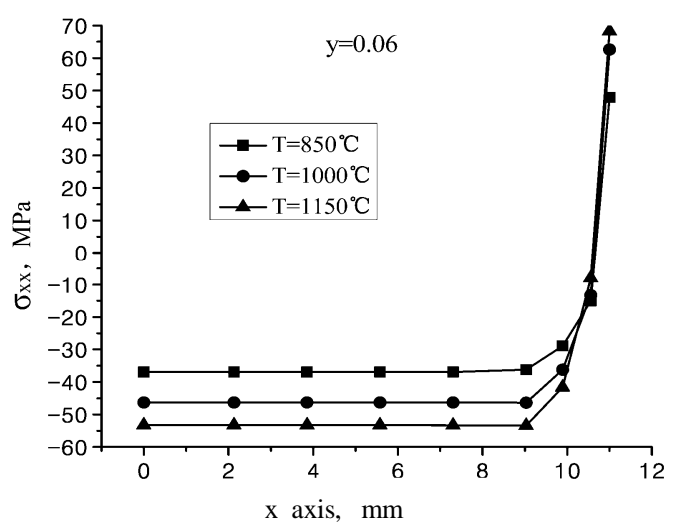

Fig.3 Variation of ceramic interfacial stress $\sigma_{\mathrm{xx}}$ along the $\mathrm{x}$-axis for different temp temperature

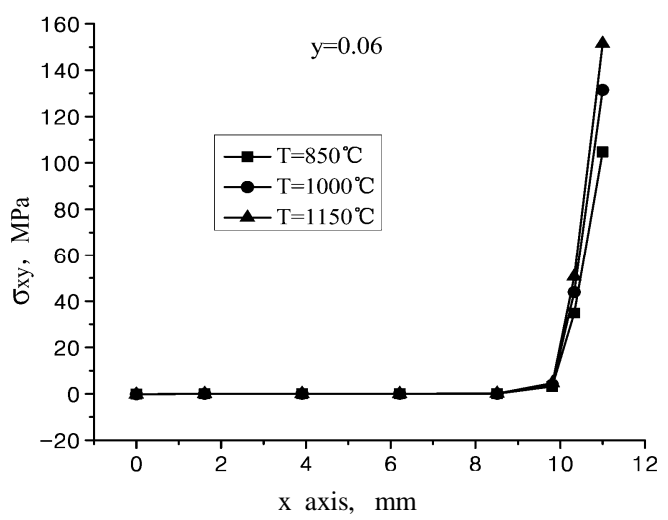

Fig.5 Variation of ceramic interfacial stress $\sigma_{x y}$ along the $\mathrm{x}$-axis for different temp temperature

Ceramic interface stress $\sigma \mathrm{xx}, \sigma$ yy and $\sigma \mathrm{xy}$ along the $\mathrm{x}$-axis are shown respectively in figure 3-5 for different temp temperature $\left(\mathrm{T}=850{ }^{\circ} \mathrm{C}, 1000{ }^{\circ} \mathrm{C}, 1150{ }^{\circ} \mathrm{C}\right)$. The compressive stress in the the ceramic side interface increases with increasing temperature, just as Fig.3 shows. It is generally 
believed that interface compressive stress $\sigma \mathrm{xx}$ in the ceramic layer is the main reason for the coating chipping away [2,7], so that, the higher the temperature is, the more likely collapse for the ceramic layer. Other layers, like base, the adhesive layer and the thermally grown oxide layer also follow the same rule. Stress $\sigma$ yy and $\sigma$ xy are relatively small, their value is almost zero, but the stresses at the edge of interface have a large mutation, and the higher the temperature, the greater the mutation (Fig.4 and 5). So the weak point of the interface bonding strength lie on the free end.

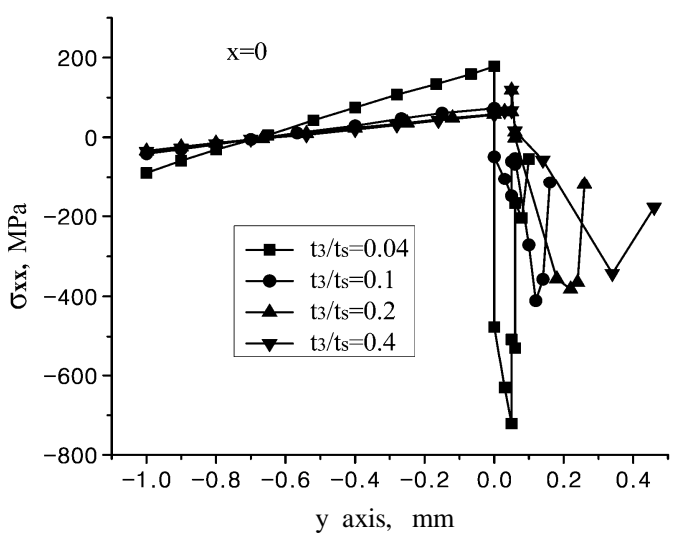

Fig.6 Variation of stress $\sigma_{\mathrm{xx}}$ along the $\mathrm{y}$-axis for different ceramic thickness

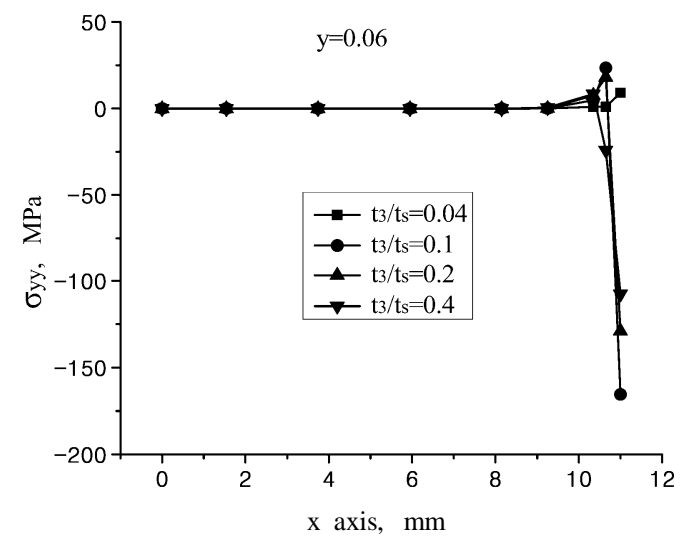

Fig.8 Variation of ceramic interfacial stress $\sigma_{\mathrm{yy}}$ along the $\mathrm{x}$-axis for different ceramic thickness

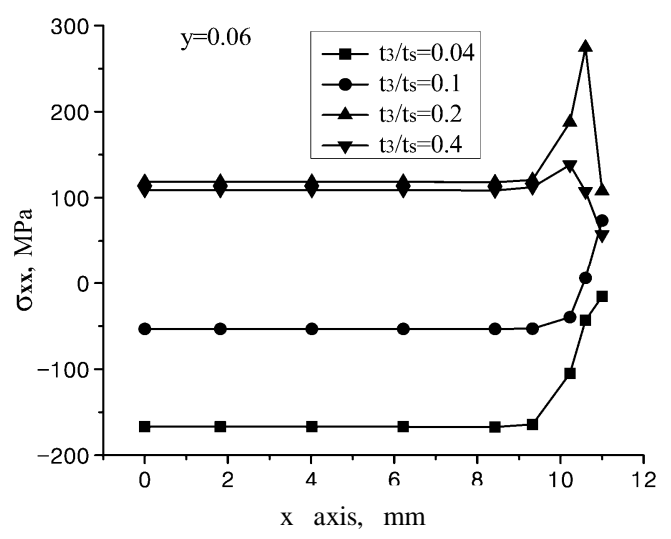

Fig.7 Variation of ceramic interfacial stress $\sigma_{\mathrm{xx}}$ along the $\mathrm{x}$-axis for different ceramic thickness

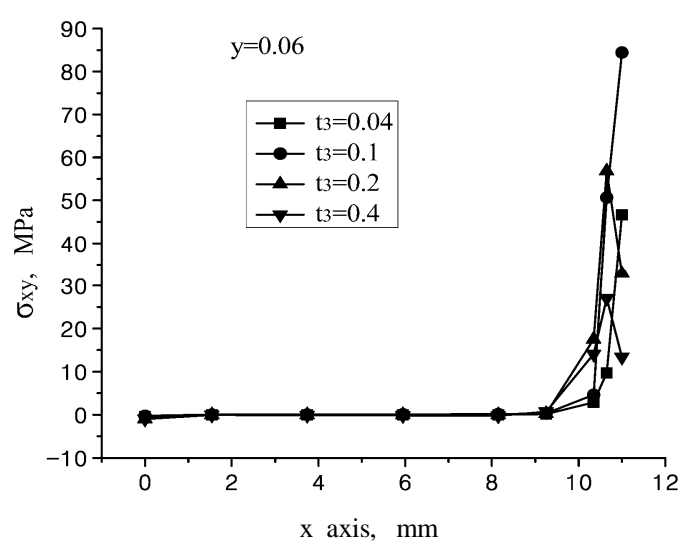

Fig.9 Variation of ceramic interfacial stress $\sigma_{x y}$ along the $\mathrm{x}$-axis for different ceramic thickness

Figures 6-9 shows that, under the temperature $\mathrm{T}=1150{ }^{\circ} \mathrm{C}$, the influence of thickness of ceramic coatings onto the stresses. Compressive stress in the ceramic layer reduce with the increase of coating thickness. When $\mathrm{t} 3 / \mathrm{ts} \leqslant 0.1$, compressive stress exist in adhesive layer and thermally grown oxide layer, while $\mathrm{t} 3 / \mathrm{ts} \geqslant 0.1$, it is tensile stress in these layers. And the thinner the coating is, the more obvious the stress $\mathrm{m}$ y axis, $\mathrm{mm} \quad \mathrm{vn}$ in fig. 6. Increase of coating's thickness makes residual stresses and interfacial stresses reduction(fig.s 7-9), when $\mathrm{t} 3 / \mathrm{ts} \geqslant 0.1$, it should be noted that stress $\sigma \mathrm{xx}$ changes from compressive to tensile in ceramic. It shows a thin coating more likely collapse for the ceramic layer. In the vicinity $x= \pm 10.5$, the tensile stress perpendicular to the interface and reach the maximum value. It is generally believed that interface tensile stress in the ceramic layer is the main reason for the coating chipping away [2,7], so the coating is easily peeled off .

\section{Summary}

(1) In ceramic layer, maximal compressive stress occurs in the place that is at the distance of $1 / 3$ thickness from coating surface, and its position will not change with temperature and the coating thickness.

(2) The increase of temperature makes stresses to rise, but does not change the distribution of stresses. The higher the temperature, the greater the compressive stress $\sigma \mathrm{xx}$, the more likely collapse 
for the ceramic layer. And as the temperature increases, the interfacial stress concentration aggravated.

(3) Increase of coating's thickness changes the distribution of stresses in the direction of thickness and makes residual stresses and interfacial stresses reduction. In the vicinity $x= \pm 10.5$, the coating is easily peeled off .

\section{References}

[1] BAI Yumei, XU Yingqiang, ZHANG Tao. A Generalized Model for Residual Stress Caused by Thermal Mismatch in Multilayer Structures. Proceedings of the 6th International Conference on Physical and Numerical Simulation of Materials Processing.2010.

[2] Hsueh C H, Becher P F, Fuller E R Jr, Langer S A and Carter W C. Surface-Roughness Induced Residual Stresses in Thermal Barrier Coating: Computer Simulations. Materials Science Forum, 1999, 308 311: 442-449.

[3] Wang Hong, Zhang Kun, Chen Guangnan.Numerical Simulation of Interfacial Stresses in Thermal Barrier Coatings Induced by interface Topography. Heat Treatment of Metals. 2001,26(9):44-46.

[4] Xi Jun, Duan Zhu ping.Variational analysis on therm-elastical stresses of plane strain problem of thermal barrier coating structure in laser radiate.High Power Laser and Particle Beams.2004, 16(11): 1397-1402.

[5] Limarga A M, Widjaja S, Yip T H, et a1. Modeling of the Effect of Al2O3 Interlayer on Residual Stress Due to Oxide Scale in Thermal Barrier Coatings. Surface and Coatings Technology. 2002.153(1):16-24.

[6] Teixeira V, Andritschky M, Fischer W, et al. Analysis of residual stress in thermal barrier coatings. Journal of Materials Processing Technology, 1999, 92-93: 209-16.

[7] Haynes J A, Ribney E D, Ferber M K and Porter W D. Oxidation and Degradation of a Plasmasprayed Thermal Barrier Coating System. Surface and Coatings Technology, 1996, 86 87: 102-108. 